\title{
Hotsite de psicologia: informações de interesse sobre anomalias craniofaciais
}

\author{
Psychology hotsite: information of interest \\ about craniofacial anomalies
}

\author{
Marina Bigeli RAFACHO' \\ Liliam D'Aquino TAVANO \\ Marisa ROMAGNOLLI' \\ Maria Irene BACHEGA
}

\begin{abstract}
Resumo
Este artigo teve como objetivo obter dados para elaborar um hotsite de Psicologia, voltado a familiares e pacientes tratados no Hospital de Reabilitação de Anomalias Craniofaciais - Universidade de São Paulo, em Bauru, estado de São Paulo, abordando temas que envolvem malformações labiopalatais e suas consequências psicológicas. Foi realizada entrevista elucidativa com 200 pais/acompanhantes e 100 pacientes em tratamento no Hospital, buscando definir seus interesses e possibilidades de utilizar um hotsite, a caracterização do perfil do usuário, o conhecimento e confiabilidade na atuação do psicólogo, e o levantamento dos temas de interesse. O hotsite foi aceito pelos entrevistados, que não só relataram interesse nesse tipo de serviço, como também acreditam nele para a resolução de suas dúvidas e anseios. Os temas de interesse citados foram a atuação do psicólogo, os aspectos da malformação e o envolvimento psicoemocional. Os resultados indicam que é viável esse tipo de acompanhamento, atendendo às necessidades individuais, momentâneas e, por vezes, emergenciais dos usuários.
\end{abstract}

Unitermos: Anormalidades craniofaciais. Fissura labial. Fissura palatina. Psicologia clínica. Psicologia em saúde.

\begin{abstract}
The aim of this article was to obtain data to develop a Psychology hotsite addressing issues involving malformation and its psychological consequences in the Hospital for Rehabilitation of Craniofacial Anomalies - Universidade de São Paulo. An informative interview was held with 200 parents/attendants and 100 patients being treated at the hospital, seeking to define their interest in and possibility of using the hotsite; characterize users' profile: knowledge of and reliability?/trust in the psychologist's actions; and survey of topics of interest. The hotsite was accepted by the interviewees, who were interested not only in the type of service but also believed in it for solving their doubts and anxieties. Mentioned Topics of interest were: the psychologist's work; aspects of malformation and its psycho-emotional involvement. The results indicate that this type of monitoring is feasible, meeting momentary individual needs, momentary, and sometimes the users'emergency needs.
\end{abstract}

Uniterms: Craniofacial abnormalities. Cleft lip. Cleft palate. Psychology clinical. Behavioral medicine.

$\cot$

1 Universidade de São Paulo, Hospital de Reabilitação de Anomalias Craniofaciais. R. Sílvio Marchioni, 3-20, VI. Universitária, 17012-900, Bauru, SP, Brasil. Correspondência para/Correspondence to: M.B. RAFACHO. E-mail: <marina.br@hotmail.com>. 
As anomalias craniofaciais são alterações congênitas que envolvem a região do crânio e da face. As mais frequentes são as fissuras de lábio e/ou palato, que, no Brasil, afetam uma em cada 650 crianças nascidas, conforme a bibliografia da área. De etiologia hereditária e/ou por fatores teratogênicos, elas ocorrem entre a $4^{\mathrm{a}}$ e a $12^{\mathrm{a}}$ semana de gestação e apresentam várias extensões e amplitudes, com protocolos e prognósticos de tratamento distintos. É possível diagnosticá-las mediante exame de ultrassonografia, porém só é possível tratá-las após o nascimento (Silva-Filho \& Freitas, 2007).

As fissuras que envolvem o palato primário podem trazer implicações estéticas; as que envolvem o palato primário e secundário, implicações estéticas e funcionais; ambas tendo consequências psicossociais (Silva-Filho \& Freitas, 2007).

Um recém-nascido com fissura de lábio e/ou palato pode apresentar dificuldades com a alimentação, com a adaptação à família (reações de aceitação ou rejeição, entre outras) e com as cirurgias que fazem parte da reabilitação. Da primeira infância até a idade adulta podem ocorrer problemas de fala, odontológicos, cirúrgicos, médicos e psicossociais. O tratamento odontológico e os procedimentos cirúrgicos são finalizados no início da idade adulta, porém o comprometimento facial raramente é totalmente reparado; o tratamento de fala é demorado, e o indivíduo pode passar a vida inteira lidando com uma desvantagem psicossocial, influenciando a qualidade de vida sua e da família (Tobiasen, 1990).

A criança com fissuras de lábio e/ou palato pode apresentar dificuldades escolares frente ao preconceito e suas consequências, como discriminação, rejeição e isolamento, gerando problemas emocionais significativos (Colares \& Richman, 2002). Intervenções, como orientação e treinamento de habilidades sociais, devem ser oferecidas para fortalecer sua autoconfiança e autoestima (Turner, Rumpsey \& Sandy, 1998)

O Hospital de Reabilitação de Anomalias Craniofaciais da Universidade de São Paulo (HRAC/USP) é um serviço público, centro de referência nacional no tratamento das fissuras, dotado de alta tecnologia. Envolve um trabalho interdisciplinar, com o objetivo de reabilitar integralmente o paciente e prepará-lo para 388 um convívio social saudável, sendo um dos poucos serviços que servem a população necessitada de tratamento especializado na área. É necessário que os pais/paciente conheçam o que é a malformação e suas implicações, bem como a complexidade do tratamento e a sua participação nesse processo (Graciano, Tavano \& Bachega, 2007).

O psicólogo, integrante dessa multidisciplinaridade, é também educador e deve estar presente desde o início do tratamento, ajudando os pais na compreensão do problema e no esclarecimento de dúvidas, de forma a auxiliá-los na superação de sentimentos como culpa e possíveis rejeições. A assistência psicológica não se restringe ao período de gestação e nascimento do filho, devendo estar presente ao longo de todo o tratamento e desenvolvimento da criança. Informações cognitivas são fornecidas durante todo o processo, em todas as suas fases, tanto para os familiares como para o paciente, de forma a desenvolver uma compreensão da complexidade deste e a possibilitar suas escolhas e caminhos.

Atualmente, a Internet vem apresentando inúmeras oportunidades para o acesso e compartilhamento de informações, com velocidade e confiabilidade (Évora, 2004; Fortim \& Consentino, 2007). Prado (2002, p.3) destaca que "O atendimento via Internet existe e tende a crescer com o passar do tempo e, por isso, não pode mais ser ignorado".

Na prática diária em hospital especializado é comum observar, nos relatos dos pais, que eles buscam na Internet informações e esclarecimentos sobre malformação. Ao mesmo tempo que revelam sentirem-se aliviados em alguns aspectos, em outros mostram-se aflitos pelo choque sofrido frente à nudez das informações. Percebem a generalidade e impessoalidade das informações, às vezes muito complexas, como as encontradas nos artigos científicos, e passam a ansiar por um diálogo humanizado para suportar tais informações.

Para Campos, Anção, Ramos, Torello e Sigulen (2001, p.2), "a demanda da sociedade por informações, orientações e mesmo consultas virtuais pela Internet já existe e necessita da análise cuidadosa de seus riscos e benefícios por parte das sociedades médica e de especialidades". Segundo Beever (2004), após o impacto da notícia, dificilmente pais e pacientes recordam as informações que lhes tenham sido passadas. O autor concluiu, ainda, ser possível utilizar a evolução da tecnologia 
para criar oportunidades para os pacientes e suas famílias terem acesso às informações de que precisam, quando precisam.

A Internet revela-se uma emergente e promissora área de prática para a profissão de psicoterapeuta (Maheu, 2001). No entanto, não se pretende aqui abraçar essa nova vertente de forma leviana, segundo o IV Princípio do Código de Ética do Psicólogo (Conselho Federal de Psicologia, 2005a, p.7): "o psicólogo atuará com responsabilidade, por meio do contínuo aprimoramento profissional, contribuindo para o desenvolvimento da Psicologia como campo científico de conhecimento e de prática". O atendimento do psicólogo pela Internet está regulamentado no Código de Ética, pela Resolução CFP no 012/2005, que dispõe a respeito de serviços mediados por computador. Esta diretiva implica também que os psicólogos, quando confrontados com novas tecnologias ou procedimentos, obedeçam às normas éticas estabelecidas quando expandem os conhecimentos profissionais, científicos e derivados (Conselho Federal de Psicologia, 2005b).

Este trabalho, embora não tenha a pretensão de substituir as consultas presenciais realizadas no Hospital, busca oferecer uma alternativa de agilização no acolhimento, orientação e ajuda, rompendo barreiras econômicas e geográficas, e oferecendo informações precisas no momento preciso, entre outras (Maheu, 2000).A intenção de utilizar essa tecnologia é viável para manter a qualidade dos cuidados de saúde. Prado (2002, p.77) sugere que "a terapia via Internet não substitui a terapia tradicional sendo esta, apenas uma alternativa, podendo complementá-la tanto em nível de serviços prestados à população como em área de pesquisa para a comunidade científica".

Em 1995, o Núcleo de Pesquisa da Psicologia em Informática (NPPI) da Clínica Psicológica Ana Maria Poppovic da Pontifícia Universidade Católica de São Paulo (PUC-SP) inicialmente informatizou o Boletim Clínico, como instrumento de comunicação e divulgação dos trabalhos de ensino e pesquisa, visando possibilitar a troca de informações, conhecimentos e experiências. Ao mesmo tempo, é um veículo de intercâmbio de experiências e informações entre as diversas Clínicas-Escola do país, na medida em que, a partir do Boletim Clínico, agilizou-se a comunicação clínica- comunidade. Atualmente, além da atualização e manutenção dessa home page, destaca-se a oferta de estágios, a supervisão de serviços informatizados (Orientação Psicológica via e-mail e Orientação Vocacional), além da oferta dos atendimentos presenciais, entre outras atividades.

Inicialmente, o link "Fale com a Clínica" visava apenas facilitar a comunicação dos trabalhos de ensino e pesquisa, criando o serviço de orientação via e-mail. No fim de 1999, chegavam mensagens de ajuda psicológica, serviço que não era oferecido à época. Essas mensagens traziam relatos de situações angustiantes e pedidos de "conselhos". Os e-mails eram respondidos com encaminhamento para um recurso da comunidade ou disponíveis na Clínica. No entanto, novas mensagens começaram a chegar, e a equipe constatou um alto grau de sofrimento psíquico, revelando ser o e-mail um novo meio pelo qual as pessoas poderiam expressar suas angústias. A partir daí, com as discussões junto ao Conselho Federal de Psicologia, a proposta do NPPI foi desenvolver um serviço de Orientação Psicológica via e-mail, buscando oferecer esse serviço da melhor forma. A partir do ano 2000, pautado pela resolução CFP no 003/2000, o serviço de psicologia via e-mail foi oficializado, inserindo um link que remete o usuário para as instruções de como utilizar o serviço (Farah, 2008). 0 serviço de Orientação via e-mail do NPPI é experimental, com seu acesso aumentando ao longo do tempo, reforçando nos autores o pensamento de que é eficaz, diferenciando das outras experiências que se dissolveram ao longo do tempo (Nolf \& Novo, 2006).

Nessa linha, o presente estudo teve por objetivo a melhoria dos atendimentos realizados no Hospital de Reabilitação de Anomalias Craniofaciais da Universidade de São Paulo, em Bauru (SP), bem como a legitimação do recurso à Internet, a partir dos estudos realizados e da constatação pública e notória de seu uso. Para tanto, buscaram-se subsídios para a implementação de um hotsite interativo, como espaço onde os pacientes e familiares possam encontrar privacidade para buscar informações e interagir com a Psicologia, além de poderem opinar, sugerir matérias de seu interesse e compartilhar ideias e experiências.

Beever (2004) observa que não basta ter a tecnologia, é preciso saber como utilizá-la para obter melhor proveito.

No Protocolo das Etapas Terapêuticas do Processo de Reabilitação das Lesões Labiopalatais do 
HRAC/USP (Universidade de São Paulo, 1993, p.5) pode-se constatar nas justificativas uma chamada ao acesso à tecnologia:

A diversidade de nosso Hospital tem permitido a apenas alguns privilegiados acesso a estes recursos. Considerando a exiguidade de recursos com a qual somos obrigados a conviver, a centralização e correta adequação dos mesmos deveria ser adotada, obedecendo a critérios de competência profissional e interesses do Hospital na área de pesquisa e tratamento.

Devido à distância geográfica dos pacientes em relação aos centros de estudo e tratamento de fissuras labiopalatinas, a Internet apresenta-se como uma oportunidade para o acesso às informações e, ao mesmo tempo, configura-se como um espaço para revelar angústias e sentimentos de forma momentânea e emergencial, bem como um feedback entre o paciente e a equipe do Serviço de Psicologia.

Este estudo teve como objetivo identificar junto aos pacientes e pais a viabilidade de acesso à Internet, bem como obter informações de seu interesse que devam constar no hotsite de Psicologia do HRAC/USP.

\section{Método}

O projeto foi aprovado pelo Comitê de Ética em Pesquisa do HRAC/USP, através do ofício no 366/ 2010 - SVAPEPE-CEP, de 12 de dezembro de 2010. Os participantes incluídos na amostra assinaram o Termo de Consentimento Livre e Esclarecido.

No período de outubro de 2008 a fevereiro de 2009 foram convidados 301 sujeitos para participar da pesquisa. Apenas um deles se negou a participar, alegando desconhecimento sobre o assunto. Dos 300 participantes da pesquisa, 100 eram pacientes do hospital, com idade entre 12 a 18 anos; 100 eram pais ou acompanhantes de pacientes com idade entre um mês e 11 anos; e 100 eram pais ou acompanhantes de pacientes com idade entre 12 e 18 anos. Quanto à caracterização dos pacientes, 54\% eram do sexo masculino e 59\% pertenciam à faixa etária entre 12 e 14 anos. Dentre os pais ou acompanhantes, a maioria (81\%) era do sexo feminino, ou seja, as mães, 11\% eram pais, e $8 \%$ outros, a maioria deles (41\%) na faixa etária entre 30 e 39 anos.

390 A maioria dos entrevistados ( $n=300$, correspondente a
73\%) era proveniente da Região Sudeste. O nível socioeconômico da amostra foi considerado Baixo Superior (63\%), classificação conforme Graciano, Lehfeld e Neves Filho (1999), critério estabelecido pela instituição.

Foram aplicados questionários específicos para cada amostra, compostos de questões abertas e fechadas. Neles foram abordadas questões referentes à caracterização dos entrevistados, conhecimentos sobre fissura, sobre a atuação do Psicólogo e sobre o acesso à Internet.

Na vinda dos pacientes ao Hospital para tratamentos ambulatoriais e/ou cirúrgicos, os sujeitos foram convidados para participar, sendo questionados sobre isso na sala de atendimento de Psicologia, pela própria pesquisadora e com auxílio de estagiários devidamente capacitados. Os questionários foram aplicados durante entrevista elucidativa, de forma a garantir o entendimento das questões e da forma como respondê-las. Para as questões abertas utilizou-se a metodologia de pesquisa qualitativa, e para a análise e interpretação dos dados, a técnica de análise de conteúdo de Bardin (2008).

\section{Resultados}

Quanto aos dados da reação dos pais ao saber da malformação, 40\% relataram choque e 31\%, choro/tristeza. Perguntados sobre qual profissional buscaram para obter para informações, 45\% apontaram informações de médicos, 11\% informações no hospital onde a criança nasceu, e 10\% relataram conhecer o HRAC.

Questionados os pacientes sobre se buscaram informações acerca de fissuras em alguma outra fonte, 27\% relataram tê-lo feito, sendo 23\% na própria família. Dentre os pacientes com acesso à Internet ( $\mathrm{n}=81), 19 \%$ afirmaram ter aí buscado informações. Questionados se buscaram esclarecer alguma dúvida no site do HRAC, $11 \%$ (9 pacientes) responderam que sim, sendo que seis as esclareceram, e três, não.

Quando questionados quanto ao uso da Internet, 69\% dos participantes ( $n=300$ ) responderam ter acesso, a maioria em casa (70\%), enquanto os demais o faziam em lan-house, trabalho, escola e outros locais. Além disso, 72\% dos entrevistados possuíam e-mail.

Ainda quanto à busca de informações pela Internet, a maioria dos pais e acompanhantes com aces- 
so (64\%) afirmou não tê-las buscado por esse meio. Dentre aqueles que o fizeram (36\%), 81\% ficaram satisfeitos com os resultados obtidos, sendo que $72 \%$ afirmaram ter encontrado as informações procuradas, contra 28\% que não as encontraram.

Em relação ao site do HRAC/USP, 42\% dos pesquisados buscaram esclarecer suas dúvidas nesse veículo. Dos entrevistados que buscaram o site, 41\% acreditam que nele faltam informações importantes, muito embora 92\% tenham ficado satisfeitos com o conteúdo.

Questionados sobre o que acreditam ser importante encontrar na Internet sobre a malformação, 54\% frisaram tratamento, causa e consequências das malformações craniofaciais.

\section{Resultados referentes à atuação do psicólogo}

Questionados os pais, acompanhantes e pacientes sobre o conhecimento do Serviço de Psicologia e sua relação com a Internet, 65\% referiram conhecer a atuação do psicólogo. Sobre acreditarem na atuação do Psicólogo via Internet, 68\% responderam positivamente. Sobre a forma do contato, 25\% mencionaram ajuda/apoio, enquanto 47\% consideraram positiva a orientação por e-mail.

Questionados se buscariam orientação psicológica pela Internet, 72\% disseram que sim. Quanto ao assunto que gostariam de conhecer, na área de Psicologia, foi citado: 16\% sobre comportamento; $11 \%$ sobre causa e tratamento do problema. Quanto à oferta do serviço de Psicologia via Internet, 86\% manifestaram interesse e 67\% relataram que expressariam suas angústias e sentimentos nesses e-mails. Assim, 88\% acreditavam ser positiva a oferta do serviço de Psicologia por Internet, por possibilitar alguma ajuda que amenizasse suas dúvidas e anseios. Ainda conforme os participantes, 93\% acreditam ser possível um diálogo entre o usuário e o Hospital, por meio desse recurso.

\section{Discussão}

Com o objetivo de auxiliar na comunicação dos usuários com o Hospital, em todas as complexas etapas do tratamento, desde o diagnóstico intrauterino até a completa reabilitação, orientando nas dúvidas, angústias e questões relacionadas ao tratamento e consequências das fissuras labiopalatinas, surgiu a ideia de implementar um hotsite de Psicologia, como meio de acesso rápido e emergencial. Com base no nível socioeconômico e cultural dos usuários, foi questionada a viabilidade e a utilidade do meio tecnológico para atender suas reais necessidades.

Como resultado, esse trabalho trouxe dados de pacientes e pais de pessoas com fissura labiopalatina, usuários do Hospital, quanto ao acesso às informações contidas na Internet, seu interesse, habilidade e possibilidade de uso desse recurso no lar, no trabalho ou outro local. As questões reveladas pelo próprio usuário nortearam os temas, que vão ao encontro de suas necessidades e devem auxiliar na elaboração e implementação do hotsite de Psicologia, propiciando um espaço para expor angústias e sentimentos de forma momentânea e emergencial, assim promovendo um feedback entre o paciente e a equipe do Serviço de Psicologia.

Embora 31\% (92) dos entrevistados não tivessem possibilidades de acesso à Internet, tinham conhecimentos a respeito e concordaram em participar da pesquisa.

O aspecto socioeconômico do brasileiro, segundo Graciano et al. (2007, p.325) tem "maior concentração nas classes baixas (71,0\% a 79,0\%), em comparação com as médias (20,0\% a 23,0\%) e altas (1,0\% a 6,0 \%)", sendo que no Hospital essa porcentagem varia em "Baixo Inferior (23,6\%), Baixo Superior (46,5\%), Médio Inferior (21,0\%), Médio (7,4\%), Médio Superior (1,4\%) e Alta (0,1\%)", refletindo a realidade brasileira e não se diferenciando da amostra deste estudo. A classificação de Graciano et al. (1999) refere-se à renda familiar em salários-mínimos, ao número de membros residentes da família, ao nível educacional da família, ao tipo e condição habitacional e ao nível ocupacional.

A maioria da amostra, embora pertencente às classes baixas, tinha acesso à Internet, seja em casa, lan-house, trabalho e/ou outro local. Esses dados correspondem aos estudos divulgados pelo Instituto Brasileiro de Opinião Pública e Estatística, segundo os quais o acesso à Internet está aumentando a cada dia no País. Considerando-se os brasileiros acima de 16 anos, cerca de 62,3 milhões de habitantes têm acesso em qualquer ambiente, seja residência, escola, trabalho, lan-house, 
biblioteca ou telecentros (Instituto Brasileiro de Opinião Pública e Estatística, 2009).

Em relação às fissuras labiopalatinas Graciano et al. (2007, p.325) afirmam que:

Sabemos que tanto o diagnóstico pré-natal, peri ou pós-natal, leva os pais a sofrerem com a perda do bebê idealizado e ao ajustamento à nova criança e suas dificuldades. Além do choque causado pelo impacto da notícia e também, muitas vezes, frente ao desconhecido haverá uma busca de informações e norteamentos para um enfrentamento positivo e à re-organização.

Para Tavano (2000, p.7):

Ao nascer uma criança com fissura labial e/ou palatal, o impacto dos pais frente a um acontecimento inesperado e frustrador, leva-os a reagir negativamente. Na maioria das vezes são denominados por sentimentos perturbadores e contraditórios.

É importante e preventivo, nesse momento, o acolhimento de profissionais especializados e orientações cognitivas pertinentes. Pode-se observar que os pais buscaram informações em diferentes fontes: com médicos, no próprio hospital onde a criança nasceu, em um hospital especializado, com coordenadores de sua cidade. Coordenadores são pais de paciente ou pacientes adultos, que voluntariamente representam o hospital em sua cidade. Cabe a eles o apoio a casos novos e a pacientes já matriculados, a divulgação do serviço do hospital, a mobilização de recursos humanos e institucionais e a organização de pacientes para garantir representatividade. Constituem um elo entre as famílias, a comunidade e o hospital, e são considerados agentes multiplicadores (Graciano et al., 2007).

A percentagem dos pais que citaram buscar orientações com médicos, foi 45\%, e 14\% deles consideraram essas orientações relevantes para ajudar no enfrentamento do tratamento das anomalias de face.

Quanto à busca de informações pela Internet, constatou-se que o número de pacientes que buscam essa via de informações ainda é pequeno.

Sobre o conhecimento das fissuras labiopalatinas no item busca de informações sobre a malformação, dos 100 pacientes entrevistados 27\% buscaram informações - com a própria família, no HRAC e na Internet.

Aqueles que buscaram informação na Internet 392 complementaram sua pesquisa com livros. Assim como é baixa a percentagem de pesquisas em sites de busca em geral, é também baixa a busca especifica ao site do HRAC-USP. No entanto, o trabalho de Roda (2007), com o objetivo de caracterizar o uso da Internet para a busca de informação sobre malformações genéticas, concluiu que hoje é frequente o uso desse instrumento para adquirir conhecimentos e facilitar a comunicação entre profissionais.

Com relação ao conteúdo de pesquisas realizadas pelos pais, a maioria buscou sobre: causas, tratamento e consequências, orientação para pais, cuidados primários de alimentação e higiene, local de tratamento, informações específicas sobre o HRAC. Alguns deles estavam satisfeitos com informações encontradas na rede, considerando-as suficientes. Nessa diferença de opiniões pode-se pensar também na habilidade de buscas às informações na Internet. Algumas pessoas têm maior ou menor dificuldade em encontrar o conteúdo desejado, talvez pelo grau de conhecimento de tecnologia. O estudo de Belloni (n.d.), com jovens que têm acesso à Internet, mostra que o nível de prática e de familiarização são variáveis que influenciam os modos de uso e os objetivos.

Os temas de interesse (abordados ou inferidos por meio das respostas e comentários) foram referentes à atuação do psicólogo, com questionamentos do tipo: "como é o trabalho, a rotina de um psicólogo?", "o que é Psicologia?"; questões quanto às consequências da malformação e seu envolvimento psicoemocional:"quais consequências a criança pode ter por estar na fase oral e ser submetida a cirurgias na boca?", "a forma que a sociedade pensa sobre a fissura", "o preconceito", "como lidar com as diferenças", "comportamentos e relacionamento mãe-filho na adolescência", "as transformações" das fases da vida, entre outros que vêm ao encontro das mesmas angústias e questionamentos apresentados dia a dia na atuação do psicólogo. Notou-se também uma dificuldade, talvez pelo fator emocional envolvido, quanto à compreensão da malformação e da situação vivida no ambiente hospitalar.

Não é raro, após um atendimento cuidadoso e atencioso, pais e/ou pacientes fazerem perguntas que demonstram não terem eles assimilado as informações. Para Tavano (2000), "a superação desse emaranhado desenrolar de estados psicológicos não é fácil e não se dá de imediato. Constitui um processo lento e contínuo, 
pleno de idas e vindas, requerendo a persistência de um acompanhamento eficaz". Nesse sentido, o atendimento ambulatorial sistemático torna-se, muitas vezes, restrito ou impossível, uma vez que os retornos ocorrem de acordo com as áreas pilares do tratamento e são dificultados pela distância geográfica, já que os pacientes procedem de todas as regiões do país.

Embora 35\% dos participantes tenham afirmado não conhecer a atuação do psicólogo, o suporte psicológico via Internet é percebido como mais acessível. Outro aspecto também associado às vantagens desse meio de comunicação é apontado por Prado (2002), Farah (2008) e Monteiro et al. (2009), quando afirmam que a orientação psicológica via Internet pode ter um caráter desinibidor e de pseudoanonimato, pois os problemas podem ser expostos sem receio de julgamentos e preconceitos, assim facilitando o contato terapêutico e promovendo a diminuição da ansiedade e a autorreflexão.

\section{Conclusão}

Este trabalho trouxe dados quanto ao acesso às informações da Internet e quanto aos interesses e possibilidades de utilizar esse recurso pelo usuário do Hospital.

Trata-se de um estudo preliminar, que mostrou alguns limites relacionados ao usuário, quando se verificou a busca de assuntos pertinentes à malformação especificamente. No entanto, revela um lado promissor quando observa que não é a dificuldade de acesso que limita esse recurso, mas, sim, o desinteresse ou o desconhecimento a seu respeito. Ao se descrever a possibilidade desse recurso, os participantes desta pesquisa compreenderam-no e se interessaram por ele, tanto por sua praticidade quanto pelo fato de possibilitar um atendimento individual e rápido, ao encontro de suas dúvidas e/ou necessidades.

O trabalho também possibilitou identificarem-se temas que poderão ir ao encontro das necessidades do público-alvo, com a consequente elaboração e implementação de um hotsite na área de Psicologia, a ser inserido no Portal do HRAC/Centrinho, já existente. Ao mesmo tempo, esse pode ser um espaço para expor angustias e sentimentos, bem como um feedback emergencial por parte dos profissionais da área.
O mundo está em evolução, a tecnologia é o futuro, e a Psicologia não pode ficar de fora, devendo sempre atentar aos benefícios e riscos que a tecnologia pode trazer. Estudos complementares ainda são necessários, bem como orientações voltadas a essa nova possibilidade. Propor um hotsite é viável, devendo ele inicialmente atender aos temas sugeridos è̀s necessidades individuais, momentâneas e, muitas vezes, emergenciais.

A Internet mostra-se como meio promissor para a divulgação de informações médicas e científicas, e seu acesso tende a crescer, assim como o interesse pelos usuários em utilizar esse serviço para amenizar suas angústias e sofrimentos. Eles encontram na Internet um espaço no qual acreditam e no qual podem expressar-se sem medo de julgamento.

\section{Referências}

Bardin, L. (2008). Análise de conteúdo. Lisboa: Edições 70.

Beever, K. (2004). Meeting the information needs of people with cancer. European Journal of Oncology Nursing, 8 (3), 193-4.

Belloni, M. L. (n.d.). Os jovens e a internet: pesquisa internacional em países ricos. Recuperado em agosto 12, 2009, disponível em <http://www.comunic. ufsc.br/ relatos_pesquisa/jovensinternetpesquisainternacional. $p d f>$.

Campos, C. J., Anção, M. S., Ramos, M. P., Torello, G., \& Sigulem, D. (2001). A consulta médica virtual: aspectos éticos do uso da internet. Psiquiatria na Prática Médica, 34 (1). Recuperado em maio 19, 2010, disponível em <http:// www.unifesp.br/dpsiq/polbr/ppm/especial05.htm>

Colares, V., \& Richman, L. (2002). Fatores psicológicos e sociais relacionados às crianças portadoras de fissuras labiopalatais. Pediatria Moderna, 38 (11), 513-516.

Conselho Federal de Psicologia. (2005a). Código de ética profissional do psicólogo. Recuperado em junho 11, 2009, disponível em <http://www.sbph.org.br/codigo_etica. $p d f>$.

Conselho Federal de Psicologia. (2005b). Resolução CFP no 012/2005. Regulamenta o atendimento psicoterapêutico e outros serviços psicológicos mediados por computador e revoga a Resolução CFP no. 003/2000. Recuperado em abril 23, 2008, disponível em <http://pol.org.br/legislacao/ pdf/resolucao2005_12.pdf>.

Évora, Y. D. (2004). As possibilidades de uso da Internet na pesquisa em enfermagem. Revista Eletrônica de Enfermagem, 6 (3), 395-399.

Farah, R. M. (2008). Orientação psicológica via e-mail: serviço oferecido pela clínica psicológica "Ana Maria Poppovic", 2002. Boletim Clínico, 13. Recuperado em fevereiro 24, 
2009, disponível em <http://www.pucsp.br/clinica/ publicacoes/boletins/boletim13_03.htm>.

Fortim, I., \& Cosentino, L. A. M. (2007). Serviço de orientação via e-mail: novas considerações. Psicologia: Ciência e Profissão, 27 (1),164-175.

Graciano, M. I., Lehfeld, N., \& Neves Filho, A. (1999). Critérios de avaliação para classificação sócio-econômica:elementos de atualização. Serviço Social \& Realidade, 8 (1),109-28.

Graciano, M. I., Tavano, L. D., \&Bachega, M. I. (2007). Aspectos psicossociais da reabilitação. In I. E. Trindade \& O. G. Silva Filho (Coord.), Fissuras labiopalatinas: uma abordagem interdisciplinar (pp.311-333). São Paulo: Santos.

Instituto Brasileiro de Opinião Pública e Estatística. (2009). Tempo de navegação do brasileiro alcança mais uma marca inédita. Recuperado em agosto 5, 2009, disponível em $<$ http://www.ibope.com.br>.

Maheu, M. M. (2000). Telehealth: the furthering of psychology as a profession. Recuperado em março 14,2009, disponível em <http://www.telehealth.net/node/29>.

Maheu, M. M. (2001). Exposing the risk, yet moving forward: a behaviorale-health model. Recuperado em agosto 6, 2010, disponivel em <http://webcache.googleusercontent. com>.

Monteiro, S., Pereira, A., Tavares, J., Vagos, P., Santos, L., \& Vasconcelos, G. (2009) Psicoterapia no ciberespaço. In J. Tavares \& A. P. Cabral (Orgs.), Anais do $2^{\circ}$ Congresso Internacional do CIDInE: novos contextos de formação, pesquisa e mediação. Recuperado em março 7, 2009, disponível em <www.ispgaya.pt/cidine/cidine2009/PAPERCIDINE/ P_PEREIRA/P_MONEIRO,\%20PEREIRA;\%20TAVARES. pdf $>$.

Nolf A., \& Novo L. C. (2006). Orientação psicológica via email do NPPI. In Conselho Regional de Psicologia de São Paulo. Psicologia \&informática: produções do III Psicoinfo ell
Jornada do NPPI. São Paulo: Conselho Regional de Psicologia de São Paulo.

Prado, O. Z. (2002). Terapia via internet e relação terapêutica. Dissertação de mestrado não-publicada, Universidade de São Paulo.

Roda, S. R. (2007). Considerações a respeito do uso da Internet como ferramenta de busca de informações sobre doenças genéticas. Dissertação de mestrado não-publicada, Universidade Estadual de Campinas.

Silva-Filho, O. G., \& Freitas, J. A. (2007). Caracterização morfológica e origem embrionária. In I. E. Trindade \& O. G. Silva Filho (Coords.), Fissuras labiopalatinas: uma abordagem interdisciplinar (pp.17-49). São Paulo: Editora Santos.

Tavano, L. A. (2000). Avaliação do desempenho psicossocial de pacientes portadores de fissuras lábio-palatina submetidos a tratamento multidisciplinar no Hospital de Reabilitação de Anomalias Craniofaciais - USP - Bauru. Tese de doutorado não-publicada, Hospital de Reabilitação de Anomalias Craniofaciais, Universidade de São Paulo, Bauru.

Tobiasen, J. (1990). Psychosocial adjustment to cleft lip and palate. In J. Bardach \& H. L. Morris (Eds.), Multidisciplinary management of cleft lip and palate (pp.820-825). Philadelphia: WB Saunders.

Turner, S. R., Rumsey, N., \& Sandy, J. R. (1998). Psychological aspects of cleft lip and palate. European Journal Orthodontics, 20 (4), 407-415.

Universidade de São Paulo. (1993). Etapas terapêuticas do processo de reabilitação das lesões lábio-palatais. Bauru: Hospital de Pesquisa e Reabilitação de Lesões Lábio-Palatais.

Recebido em: 23/2/2011

Versão final reapresentada em: 22/11/2011

Aprovado em: 20/12/2011 